\title{
PEMANFAATAN CAMPURAN ZEOLIT DAN FLY ASH BATUBARAYANG TELAH DIAKTIVASI FISIK TERHADAP AKSELERASI MESIN SEPEDA MOTOR 4-LANGKAH
}

\author{
Herry Wardono ${ }^{1}$, A Yudi Eka Risano ${ }^{2}$, Adi Ernadi ${ }^{3}$ \\ Jurusan Teknik Mesin, Fakultas Teknik Universitas Lampung \\ Jln. Prof.Sumantri Bojonegoro No.1 Gedung H FT Lt.2 Bandar Lampung \\ Telp. (0721) 3555519, Fax.(0721) 704947 \\ Email: herry.wardono@eng.unila.ac.id ${ }^{1}$,yudi_95@yahoo.com², adiernadi123@yahoo.com³
}

\begin{abstract}
Abstrak
Konsumsi energi dalam negeri Indonesia cukup tinggi, hamper 96\% dipenuhi dari bahan bakar fosil (minyak bumi 48\%, gas 18\% dan batubara 30\%). Dari total konsumsi tersebut, dapat terlihat bahwa hamper 50\% merupakan Bahan Bakar Minyak (BBM). Oleh karena itu, perlu dilakukan upaya penghematan pemakaian bahan bakar. Salah satunya adalah dengan cara memanfaatkan campuran zeolit dan fly ash sebagai filter udara kendaraan. Karena zeolit dan fly ash memiliki kemampuan untuk menangkap gas nitrogen dan uap air dalam udara, sehingga hanya gas oksigen yang masuk ke dalam ruang bakar. Dengan demikian proses pembakaran semakin optimal dan prestasi mesin semakin baik. Sebelum digunakan, zeolit dan fly ash dicampur dengan komposisi campuran zeolit 0\%: fly ash 100\%, zeolit 25\%: fly ash 75\%, zeolit 50\% : fly ash 50\%, zeolit 75\% : fly ash 25\%, dan zeolit $100 \%$ : fly ash 0\%. Campuran zeolit dan fly ash tersebut dibuat dalam bentuk pelet lalu diaktivasi fisik dengan suhu $100^{\circ} \mathrm{C}$ (alami), $150{ }^{\circ} \mathrm{C}, 175^{\circ} \mathrm{C}, 200{ }^{\circ} \mathrm{C}$, dan $225^{\circ} \mathrm{C}$. Sedangkan variasi massa filter yang digunakan adalah 50\% (13,75 gram), 75\% (20,62 gram) dan 100\% (27,50 gram). Pelet tersebut disusun menyerupai filter dan diletakkan pada lubang filter udara kendaraan. Pengujian ini bertujuan untuk mengetahui pengaruh temperatur aktivasi dan variasi massa filter serta komposisi campuran zeolit dan fly ash terhadap prestasi motor bensin 4-langkah dilihat dari hasil akselerasi. Akselerasi terbaik adalah sebesar 12,61\% (lebih cepat 2,41 detik) yang terbaik pada pengujian menggunakan filter dengan campuran Z50:F50, variasi massa $100 \%$ dan temperatur $225^{\circ} \mathrm{C}$.
\end{abstract}

Kata kunci : Filter zeolit,-fly Ash batubara, adsorben udara, akselerasi mesin

\begin{abstract}
Energy consumption in Indonesia is quite high, almost $96 \%$ is supplied from fossil fuel ( crude oil 48\%, gases 18\%, and coal 30\%). From the total of energy consumption, it can be seen that almost $50 \%$ is gasoline. Thus, it is necessary to attain a certain aim in saving fossil fuel consumption. One of the ways is the utilization of zeolite and coal fly ash mixture as engine air filter. The mixture of zeolite and coal fly ash have a specific ability to trap nitrogen gases and water vapor in air, so that only oxygen enters the combustion chamber. Thus, the combustion process reaches the optimal condition and engine performance works better. Before applying, zeolite and fly ash were mixed with the comparisons of zeolite 0\%: fly ash 100\%, zeolite $25 \%$ : fly ash $75 \%$, zeolite 50\% : fly ash 50\%, zeolite 75\% : fly ash 25\%, and zeolite 100\% : fly ash 0\%. The mixture of zeolite and fly ash was made in the form of pellet and activated physically within the temperature of $100{ }^{\circ} \mathrm{C}$ (naturally), $150{ }^{\circ} \mathrm{C}, 175{ }^{\circ} \mathrm{C}, 200{ }^{\circ} \mathrm{C}$, and $225{ }^{\circ} \mathrm{C}$. Wheres various mass filter used were $50 \%$ (13,75 grams), 75\% (20,62 grams) and $100 \%$ (27,50 grams). The pellets were arranged resemble a filter and place on the case of engine air filter. The purpose of this testing is to find out the effect of temperature activation and the filter mass variations
\end{abstract}


as well as the composition of zeolite and fly ash mixture toward the performance of four step gasoline engine in acceleration testing. The best acceleration achieved is $12,61 \%(2,41$ seconds faster ) taken from the test using filter of Z50:F50 mixture, with mass variation of $100 \%$ within temperature of $225^{\circ} \mathrm{C}$.

Keywords: Filter of zeolite and coal fly ash,air adsorbent, engine acceleration.

\section{PENDAHULUAN}

Berdasarkan statistik data dari Kementrian Energi dan Sumber Daya Mineral, Pada tahun 2006, konsumsi BBM di Indonesia sejumlah 58,5 juta kilo liter (kl). Porsi terbesar adalah solar (25 juta kl), disusul oleh premium (17 juta kl), dan minyak tanah (4 juta kl). Delapan tahun berselang (2014), penggunaan BBM di Indonesia melonjak menjadi 70,8 juta $\mathrm{kl}$, yang masih di dominasi oleh solar $(32,6$ juta kl), premium (29,7 juta kl) dan minyak tanah (1,9 juta kl), dan akan terus bertambah seiring dengan berjalannya waktu. Dengan keadaan seperti ini, maka dibutuhkan solusi untuk mencari sumber energi alternatif [2].

Salah satunya adalah pemanfaatan mineral alam zeolit dan fly ash batu bara sebagai penyaring udara pembakaran. Karena pada prinsipnya, Zeolit memiliki kemampuan dalam menangkap gas nitrogen dalam udara, hal ini didasarkan atas sifat-sifat mineralogi, fisik dan kimia yang dimiliki zeolite.Zeolit yang diaktivasi Fisik mempunyai kemampuan sebagai adsorben lebih baik dibandingkan dengan zeolit yang tanpa aktivasi, karena aktivasi fisik sendiri bertujuan untuk menghilangkan uap air yang ada pada poripori zeolit sehingga pori-pori zeolit akan banyak yang kosong, sehingga kemampuan adsorbsinya akan meningkat. [1]. Sedangkan fly ash batubara memiliki kemampuan dapat menyerap air dan beberapa unsur hara sehingga dapat meningkatkan kualitas adsorbsi dengan baik [4]. Sehingga, pemanfaatan zeolit dan fly ash sebagai filter udara kendaraan yang bertujuan untuk meningkatkan prestasi mesin dapat tercapai.

Kemampuan fly ash dalam meningkatkan kualitas proses pembakaran telah dibuktikan oleh Dimas Rilham Purnawanta tahun 2012. Pembuatan dan pengujian fly ash pelet teraktivasi fisik dengan variasi massa yang berbeda yaitu 55,45 , dan 35 gram pada motor bensin 4 langkah, yaitu untuk massa 45 gram sebesar 22,23 gram dan pada pengujian statisioner dapat menghemat konsumsi bahan bakar hingga sebesar 21,23\%.[5]. Selain itu, kemampuan zeolit dalam meningkatkan kualitas proses pembakaran telah dibuktikan oleh Mahdi (2006). Peningkatan daya engkol diperoleh sebesar $0,215 \mathrm{~kW}$ $(12,088 \%)$ pada penggunaan zeolit dengan diameter $1,4 \mathrm{~mm}$, berat pelet $200 \mathrm{gr}$, temperatur aktivasi $325^{\circ} \mathrm{C}$, waktu pemanasan selama 2 jam, dan putaran mesin 2000 rpm. Penurunan konsumsi bahan bakar spesifik terbaik adalah dengan diameter pelet $0,7 \mathrm{~mm}$, berat 200 gram, dengan temperatur aktivasi $352^{\circ} \mathrm{C}$, waktu pemanasan selama 2 jam dan putaran mesin $1100 \mathrm{rpm}$ yaitu sebesar $0,0123 \mathrm{~kg} / \mathrm{kWh}$ $(9,729 \%)[3]$.

Kemampuan zeolit - fly ash dalam meningkatkan kualitas proses pembakaran telah dibuktikan juga oleh Eko Aprilando Sinulingga (2016). Penggunaan pelet filter zeolit-Fly Ash tanpa aktivasi (alami) sebagai filter udara kendaraan berhasil menghemat konsumsi bahan bakar pada pengujian stasioner yaitu pada penggunaan pelet filter (Z25-F75) 1 variasi massa $75 \%$ $(11,25 \mathrm{gr})$ sebesar $53,06 \%(7,66 \mathrm{ml}$ dari $16,333 \mathrm{ml}$ ) pada uji stasioner, serta mampu mereduksi waktu tempuh kendaraan hingga $21 \%$ pada uji akselesari.

\section{METODE PENELITIAN}

\section{Persiapan Filter Zeolit dan Fly ash}

Penelitian ini membutuhkan beberapa langkah persiapan yang harus dilakukan. Langkah pertama adalah 
menumbuk batu zeolit hingga ukurannya kecil sehingga mudah untuk diayak. Selanjutnya, zeolit dan fly ash diayak dengan ukuran 100 mesh untuk mendapatkan ukuran partikel yang seragam. Setelah itu, zeolit dan fly ash dibuat dalam bentuk pelet dengan perbandingan campuran $42 \%$ air mineral, $4 \%$ tepung tapioka dan 54\% adalah campuran komposisi antara zeolit dan fly ash. Langkah selanjutnya dalam membuat pelet filter adalah menentukan kandungan persentase bahan pelet. Dicontohkan membuat 300 gram bahan pelet dengan campuran perbandingan $50 \%$ air, $4 \%$ perekat, $46 \%$ bahan fly ash dan zeolit. Berikut ini perhitungannya:

Air $50 \%=300 \times \frac{50}{100}=150$ gram

Perekat $4 \%=300 \times \frac{4}{100}=12$ gram

Zeolitfly ash dan $46 \%=300 \times \frac{46}{100}=138$ gram

Prosedur pembuatan adonan ini adalah air dan tepung tapioka dicampur lalu diaduk sambil dipanaskan hingga membentuk seperti lem, selanjutnya zeolit dan fly ash dicampurkan dan diaduk hingga kalis. Selanjutnya, setelah itu adonan diratakan menggunakan ampia dengan ketebalan 3mm, dan dicetak dengan diameter $10 \mathrm{~mm}$. Hasil cetakan diletakkan pada meja dan dibiarkan pada temperatur ruangan selama 24 jam hingga menjadi kering dan siap untuk dilakukan pengovenan (aktivasi). Setelah didiamkan selama 24 jam pada suhu ruangan, langkah selanjutnya adalah melakukan aktivasi fisik terhadap pelet filter zeolit-Fly ash. Aktivasi fisik pelet filter zeolit-Fly ash ini dilakukan dengan menggunakan oven listrik dan proses aktivasi fisik hanya dilakukan selama 60 menit.
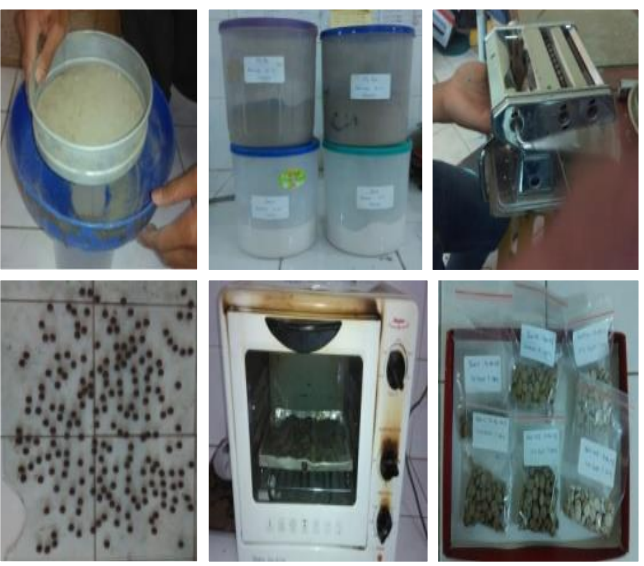

Gambar 1. Proses aktivasi fisik

Setelah dilakukan aktivasi fisik, pelet campuran zeolit dan fly ash tersebut dikemas dalam plastik kedap udara dengan tujuan agar tidak terkena udara secara langsung. Setelah semua persiapan telah selesai, barulah pelet campuran zeolit dan fly ash siap untuk dikemas dengan kawat strimin yang bentuknya mengikuti pola filter udara kendaraan yang nantinya akan diletakkan pada rongga filter udara kendaraan uji. Ada 2 parameter yang digunakan untuk memisahkan pelet campuran zeolit dan fly ash yang telah diaktivasi fisik. Parameter yang pertama yaitu memisahkan sesuai dengan temperatur aktivasi fisiknya, dimana temperatur yang dipakai pada pengujian ini yaitu $100^{\circ} \mathrm{C}$ (alami), $150{ }^{\circ} \mathrm{C}, 175^{\circ} \mathrm{C}, 200$ ${ }^{\circ} \mathrm{C}$, dan $225{ }^{\circ} \mathrm{C}$. Parameter kedua yaitu memisahkan sesuai dengan variasi massa yang akan digunakan dalam penelitian ini yaitu massa $100 \%$ (27,50 gram), $75 \%$ (20,62 gram), dan 50\% (13,75 gram).
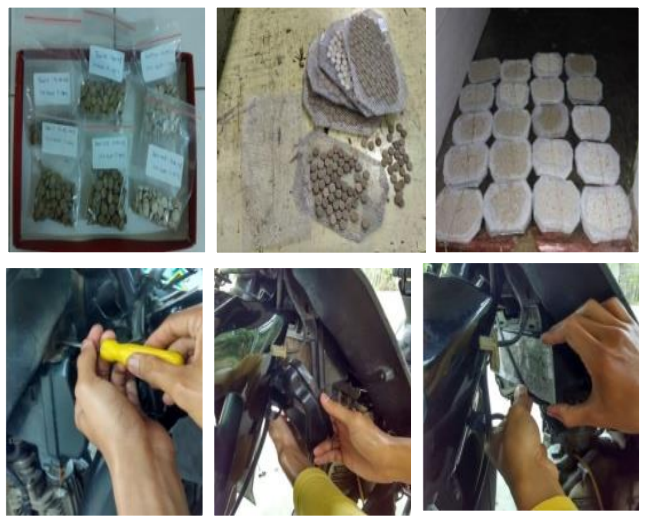

Gambar 2. Pembuatan dan pemasangan filter 


\section{Persiapan kendaraan uji}

Kendaraan uji yang dipakai dalam pengujian ini adalah sepeda motor produk Honda dengan tipe Supra Fit tahun pembuatan 2005 yang memiliki kapasitas mesin sebesar $100 \mathrm{cc}$.

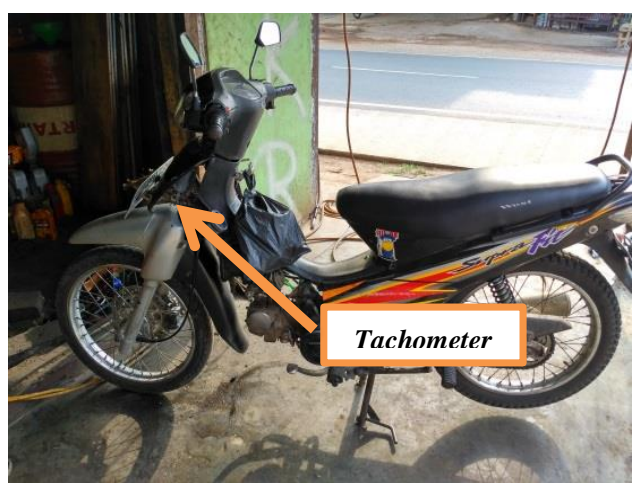

Gambar 3. Sepeda motor uji

Langkah pertama yang harus dilakukan sebelum melakukan pengujian adalah kendaraan uji dipasangkan tachometer untuk mengetahui kecepatan putaran mesin dan digunakan sebagai acuan untuk melakukan perpindahan perseneling pada saat pengujian dilakukan, sehingga perlakuan terhadap tiap-tiap filter uji pada saat pengujian menjadi sama. Hal lain yang perlu diperhatikan adalah kendaraan uji yang digunakan untuk pengujian harus di tune-up terlebih dahulu agar sepeda motor dalam kondisi baik, dan selama dilakukannya proses pengujian, sepeda motor dilakukan servis secara berkala untuk menjaga kondisi motor agar selalu dalam kondisi baik pada setiap pengujian dan tentunya akan mendapatkan hasil yang maksimal.

\section{Prosedur Pengujian}

Pengujian ini dilakukan untuk mengetahui perbandingan waktu tempuh kendaraan (akselerasi) yang menggunakan filter zeolit-fly ash dan tanpa menggunakan filter zeolit-fly ash. Pengujian ini ada 3 proses, pengujian yang pertama menentukan temperatur aktivasi fisik terbaik, pengujian kedua menentukan variasi massa terbaik dan yang ketiga pengujian menentukan komposisi campuran zeolit dan fly ash terbaik. Adapun parameter pengujian prestasi mesin sebagai berikut:

\section{Pengujian Akselerasi}

Pengujian ini dilakukan untuk melihat waktu tempuh akselerasi kendaraan uji dari keadaan diam $0 \mathrm{~km} / \mathrm{jam}$ hingga mencapai kecepatan $80 \mathrm{~km} / \mathrm{jam}$ dilakukan pada sebuah lintasan lurus dengan panjang lintasan kurang lebih $1 \mathrm{~km}$.

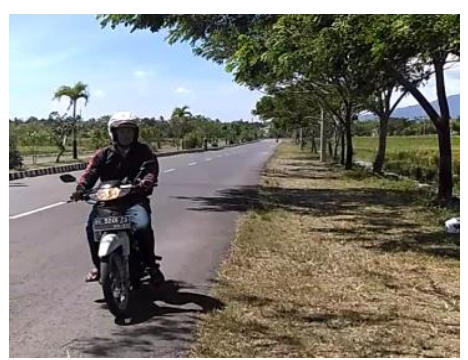

Gambar 4. Lintasan uji akselerasi

Pada pengujian akselerasi ini, ada beberapa prosedur yang harus dilakukan, prosedur pengujian yang pertama yaitu menghidupkan mesin kendaraan, masukan perseneling gigi 1. Ketika gas akan melaju, gas diputar bersamaan dengan menekan tombol start pada stopwacth. Setelah melaju, perseneling dipindahkan dengan sesuai dengan parameter yang telah ditentukan. Perpindahan perseneling untuk setiap filter uji mendapatkan perlakuan yang sama. Perpindahan perseneling dari gigi 1, 2, 3, sampai dengan gigi 4 dilakukan pada saat kecepatan putaran mesin mencapai $5500 \mathrm{rpm}$. Pada saat kendaraan uji telah mencapai kecepatan $80 \mathrm{~km} / \mathrm{jam}$ lalu menekan tombol stop pada stopwacth dan kemudian merekam waktu tempuh pengujian yang dilakukan. Pengujian dilakukan sebanyak 3 kali pengulangan untuk masing-masing filter lalu diambil rata-rata pengujian filter dan didapatkan data persentase pengaruh filter terhadap prestasi mesin.

\section{HASIL DAN PEMBAHASAN}

Pengujian dilakukan pada kondisi cuaca cerah temperatur lingkungan $27^{\circ} \mathrm{C}$ $31^{\circ} \mathrm{C}$. Proses pertama pengujian ini adalah menentukan suhu aktivasi terbaik yang akan digunakan untuk pengujian. Proses ini 
dilakukan dengan menggunakan campuran zeolit-fly ash (50\%: 50\%) dan temperatur aktivasi fisik untuk percobaan yang digunakan antara lain : $100{ }^{\circ} \mathrm{C}$ (alami), $150^{\circ} \mathrm{C}, 175^{\circ} \mathrm{C}, 200^{\circ} \mathrm{C}$, dan $225^{\circ} \mathrm{C}$.

Setelah mendapatkan temperatur aktivasi terbaik, proses selanjutnya adalah pengambilan data pengujian. Pengujian dilakukan dengan menggunakan 5 variasi komposisi dan 3 variasi massa filter. Variasi massa yang digunakan antara lain : massa $100 \%$ (27,50 gram), $75 \% \quad(20,62$ gram), dan $50 \%$ (13,75 gram). Sedangkan variasi komposisi campuran antara Zeolit dengan Fly ash yaitu Zeolit 0\%: Fly ash 100\% (Z0:F100), Zeolit 25\% : Fly ash 75\% (Z25:F75), Zeolit 50\% : Fly ash 50\% (Z50:F50), Zeolit 75\% : Fly ash 25\% (Z75:F25), Zeolit 100\% : Fly ash 0\% (Z100:F0). Berikut penyajian data pengujiannya.

\section{Menentukan suhu aktivasi fisik terbaik dan variasi massa terbaik}

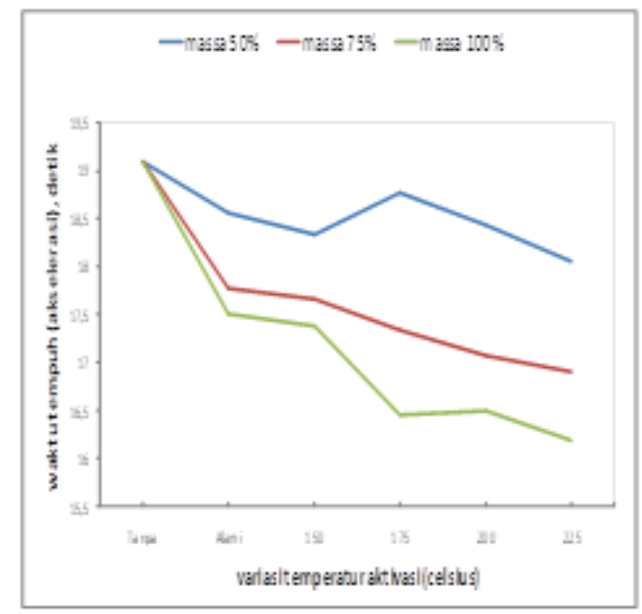

Gambar 5. Pengujian untuk menentukan temperatur aktivasi dan variasi massa terbaik

Dari pengujian yang telah dilakukan, dapat dilihat bahwa temperatur aktivasi fisik mampu mempengaruhi waktu tempuh kendaraan (Akselerasi). Pada pengujian tanpa filter, waktu tempuh kendaraan sebesar 19,10 detik. Pada pengujian menggunakan variasi massa $50 \%$, akselerasi yang terbaik adalah pengujian menggunakan filter dengan temperatur aktivasi $225{ }^{0} \mathrm{C}$ dengan hasil
18,05 detik, lebih cepat 1,05 detik dibandingkan pengujian tanpa filter dengan mereduksi waktu tempuh kendaraan sebesar 5,49\%. Pada pengujian menggunakan variasi massa $75 \%$, akselerasi terbaik adalah pengujian menggunakan filter dengan temperatur aktivasi $225{ }^{\circ} \mathrm{C}$ dengan hasil 16,91 detik, lebih cepat 2,19 detik dibandingkan pengujian tanpa filter dengan mereduksi waktu tempuh kendaraan sebesar 11,46\%. Pada pengujian menggunakan variasi massa $75 \%$, akselerasi yang terbaik adalah pengujian menggunakan filter dengan temperatur aktivasi $225{ }^{0} \mathrm{C}$ dengan hasil 16,19 detik, lebih cepat 2,91 detik dibandingkan pengujian tanpa filter dengan mereduksi waktu tempuh kendaraan sebesar 15,23\%. Sehingga untuk menentukan komposisi campuran zeolitFly ash terbaik akan menggunakan temperatur aktivasi fisik $225{ }^{0} \mathrm{C}$ dan menggunakan variasi massa $100 \%(27,50$ gram).

\section{Menentukan komposisi campuran zeolit- fly ash terbaik}

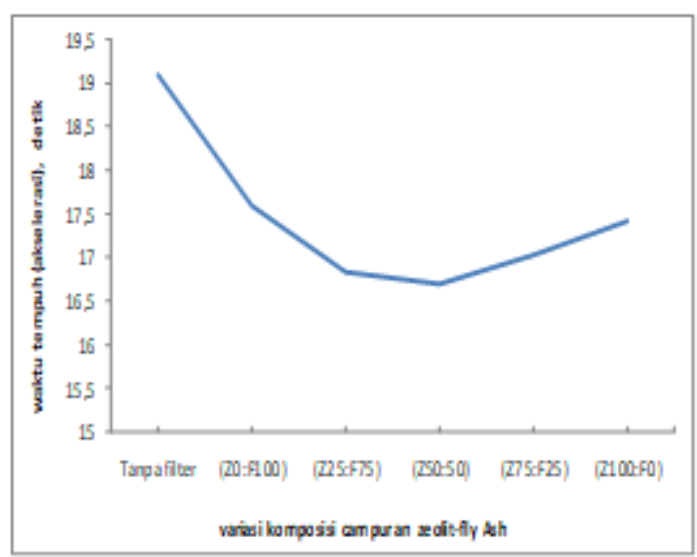

Gambar 6. Waktu tempuh uji akselerasi dalam menentukan komposisi campuran zeolit-fly ash terbaik.

Pada pengujian ini, temperatur aktivasi fisik pelet yang digunakan adalah $225{ }^{\circ} \mathrm{C}$ dan menggunakan variasi massa filter $100 \%$. Pada pengujian yang telah dilakukan, menunjukan bahwa penggunaan filter dengan variasi komposisi mampu mereduksi waktu tempuh kendaraan (menaikkan akselerasi). 
Dari gambar 5, terlihat bahwa pengujian menggunakan filter dengan variasi komposisi Z50:F50 menjadi filter dengan waktu tempuh kendaraan terbaik dengan catatan waktu 16,69 detik, hasil tersebut lebih cepat 2,41 detik dibandingkan dengan pengujian tanpa menggunakan filter (menaikan akselerasi sebesar 12,61\%). Peringkat kedua terbaik adalah filter dengan komposisi Z25:F75 dengan cacatan waktu 16,82 detik, dengan waktu tempuh yang lebih cepat 2,28 detik dibandingkan dengan pengujian tanpa menggunakan filter (menaikkan akselerasi sebesar 11,93\%). Dan untuk peringkat ketiga terbaik yaitu filter dengan komposisi Z75:F25 dengan cacatan waktu 17,03 detik dengan waktu tempuh yang lebih cepat 2,07 detik dibandingkan dengan pengujian tanpa menggunakan filter (menaikkan akselerasi sebesar 10,83\%).

\section{KESIMPULAN}

Aktivasi fisik terhadap pelet zeolitfly ash terbukti mampu mereduksi waktu tempuh kendaraan uji (meningkatkan akselerasi). Dengan filter terbaik dari keseluruhan pengujian adalah filter komposisi zeolit 50\% : Fly ash 50\% (Z50:F50) dengan waktu tempuh lebih cepat 2,41 detik dibandingkan dengan pengujian tanpa menggunakan filter (menaikkan akselerasi sebesar 12,61\%).

\section{REFERENSI}

[1]. Al-Chemi. 2012. Sejarah, Fungsi Dan Struktur Zeolit. Http://Datachem.Blogspot.Co m/2011/01/Sejarah-Fungsi-

Dan-StrukturZeolit. Html. Diakses pada 3 Desember 2016.

[2]. Kementrian ESDM, 2015. Jawaban Kebutuhan Energi Nasional. Jakarta.

Http://Www.Esdm.Go.Id/Asse ts/Admin/

File/Pub/Outlook_Energi_201

2.Pdf. Diakses pada 23 Januari
2017.

[3]. Mahdi. 2006. Pengaruh Pemanfaatan Zeolit Yang Diaktivasi Fisik Pada Beragam Temperatur Dan Waktu Pemanasan Terhadap Kinerja Motor Diesel 4-Langkah. Skripsi Program Sarjana Jurusan Teknik Mesin-Fakultas Teknik Universitas Lampung. Bandar Lampung.

[4]. Rilham, Dimas. 2012. Pengaruh Aplikasi Fly ash Bentuk Pelet Perekat Yang Diaktivasi Fisik Terhadap Prestasi Mesin Dan Emisi Gas Buang Sepeda Motor Bensin 4-Langkah. Skripsi Program Sarjana, Jurusan Teknik Mesin. Universitas Lampung. Bandar Lampung.

[5]. Sinulingga, Eko. 2016. Penggunaan Fly Ash Dan Zeolit Untuk Menghemat Konsumsi Bahan Bakar Dan Mereduksi Emisi Gas Buang Sepeda Motor Bensin 4-Langka. Skripsi Program Sarjana, Jurusan Teknik Mesin. Universitas Lampung. Bandar Lampung. 